\title{
Electronic Circuit Failure Detection Using Thermal Image
}

\author{
Azrul Mahfurdz, Rohaizan Saher, Wan Ghani Wan Pi \\ Electrical Engineering Department, Politeknik Sultan Haji Ahmad Shah, Kuantan, Pahang \\ Email: azrulpmu@yahoo.com.my
}

How to cite this paper: Mahfurdz, A., Saher, R. and Pi, W.G.W. (2020) Electronic Circuit Failure Detection Using Thermal Image. Open Access Library Journal, 7: e6662. https://doi.org/10.4236/oalib.1106662

Received: July 25, 2020

Accepted: August 23, 2020

Published: August 26, 2020

Copyright $\odot 2020$ by author(s) and Open Access Library Inc.

This work is licensed under the Creative Commons Attribution International License (CC BY 4.0).

http://creativecommons.org/licenses/by/4.0/

(c) (i) Open Access

\begin{abstract}
This inspection of electronic circuits can be performed either by connection with voltage supply and without voltage supply. However, inspections during the working circuit may invite serious harm and damage to the components in the circuit. Usually, the method used is to measure the current and voltage values in the circuit based on the reading reference when the circuit is in normal condition. There is another method that can help check the current circuit condition by using image processing method. In this paper, we presented our study on electronic component failure detection using thermal image processing. The thermal image was collected from linear regulated $\mathrm{dc}$ power supply. The observation is focused on the thermal produce by capacitor and voltage regulator IC. The image has been analysed using Red Green Blue (RGB) and Hue Saturation Value (HSV) colour space. The pixel of colour was analysed using mean value. The result showed there is significant different heat produced by the component in normal condition and failure condition. Through the observation, it was found that the high heat was recorded if wrong polarity of the components in the circuit.
\end{abstract}

\section{Subject Areas}

Electronic Engineering

\section{Keywords}

Thermal Image, Colour Space, Electronic Circuit, Image Processing

\section{Introduction}

The thermal camera has been developed in recent decades and now become a new type detection technology. The first thermographic camera (night vision) was introduced in 1929 by KalmanTihanyi for anti-aircraft defense in Britain. 
Thermal infrared (TIR) imagers typically operate in the midwave ( 3 to $5 \mu \mathrm{m}$ ) or long-wave ( 8 to $14 \mu \mathrm{m}$ ) infrared region [1]. Basically objects that are detected by thermographic cameras depend on the temperature difference of the object and the surrounding temperature conditions.

Nowadays, detection technology using thermal image is rapidly increasing and being used in various applications. The study of pipe leakage found that thermal images were one of the most accurate methods of detecting gas leakage [2] [3]. This technique also can be applied to detect breast cancer [4]. Other than that, study on bacteria detection showed that each pixel from the thermal image presented a different temperature colour due to the thousands of bacteria contained in it [5]. The study on early detection of land slide demonstrated that temperature and colour indication play important role in indicated the spots of water saturation position [6]. Besides that, thermal image camera has been proved that can detect buried object and discovered that there is significant different image capture during day times and night times [7].

Thermal imaging can be used in various electrical applications such as cable boards, bus bar systems, overhead wires, electrical machines and drives, electrical equipment in mobile installations [8]. This technique is also used in detecting equipment damage, connection and damage of electronic components [8] [9] [10] [11]. IC testing using heat techniques found that this method increases the efficiency of the test system in finding IC defects in PCB [12]. In addition, this method is also used in detecting short-circuits for electric motors. According to a previous research, fault component can be detected using thermal image, because some object will produce heat whether in the hottest or in the coolest situation.

The practical process of teaching in the electrical engineering lab requires the lecturer to examine the student's circuit. This process is important to avoid any damage to the appliance when the circuit is switched on. Often the components damage due to incorrect connection and reverse polarity. Additionally, this condition still occurs although the circuit has been checked manually. Although, there are many electrical devices that can be used to check circuit conditions, there is an alternative method that can be used to detect faults in components which is thermal imagery. In this paper, the thermal image is proposed to detect fault electronic component. This paper is focused on incorrect connection and reverse polarity for Regulator Voltage IC and capacitor.

\section{Methodology}

The method in this study involves 4 sections namely data collection, image cropping, filtering and feature colour extraction and decision. The methodology process is showed in Figure 1. Data collection is the process whereby how the data were collected. In this section, the device (thermal camera) and MATLAB software are used in order to get the data. Image cropping can be defined as the process that we want to resize the image and focus at the interest area. The next section is filtering process which is image is enhanced by image filtering and 
noise removing. The thermal image is then through the features extraction section to extracted colour information from each image samples.

Sample image were acquired by using a thermal camera and all image will be transfer to computer. Thermal camera used for this project is FLIR C2 Compact Thermal Imaging Camerathat has 4800 measurement pixels. For this project, heat condition produce by capacitor and voltage regulator IC will be observed. The circuit used in this project is linear regulated dc power supply as shown in Figure 2 bellow.

Linear regulated dc power supply circuit used in this study has three sections which is brdge rectifier, filter and voltage regulator. The bridge rectifier section consists of four diodses (D1-D4), while the filter section consists of 2 capacitors $(\mathrm{C} 1 \& \mathrm{C} 2)$ and the voltage regulator section using IC LM7812.

\section{Result and Analysis}

The thermal image from FLIR C2 Camera has been analysed for capacitor and voltage regulated IC. The image was observed at normal and failure condition. The sample image then was cropped and filtered using MATLAB software. In this study, mathematical statistic of the image has been analysed using different colour space which is Red Green Blue (RGB) and Hue Saturation Value (HSV). The comparison normal and failure condition image was showed in Figure 3 and Figure 4.

Based on the general observation the image showed a significant difference between the two conditions. The heat will be freed by the components and can be clearly seen in Figure 3. Table 1 showed the mean value of RGB and HSV.

Through the mean analysis of RGB and HSV colour space, there is significant difference in RGB colour space. For the analysis obtained from the mean value of HSV the difference is too small. Significant differences occurred in the RGB analysis where the normal values and the component failure values were compared as shown in Figures 5-8. Red and green components for incorrect connections increased for both components (C2 and IC1).

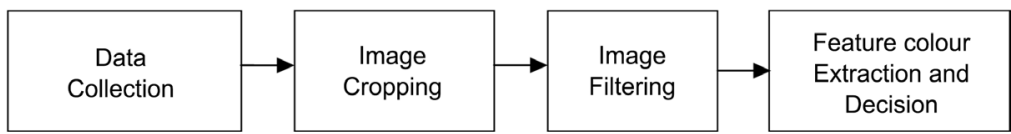

Figure 1. Methodology process.

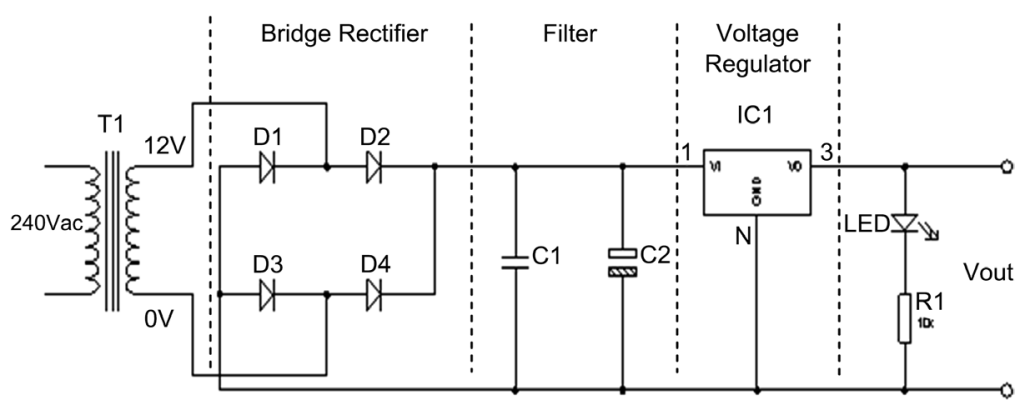

Figure 2. Linear regulated dc power supply. 
Table 1. Mean value of RGB and HSV colour space.

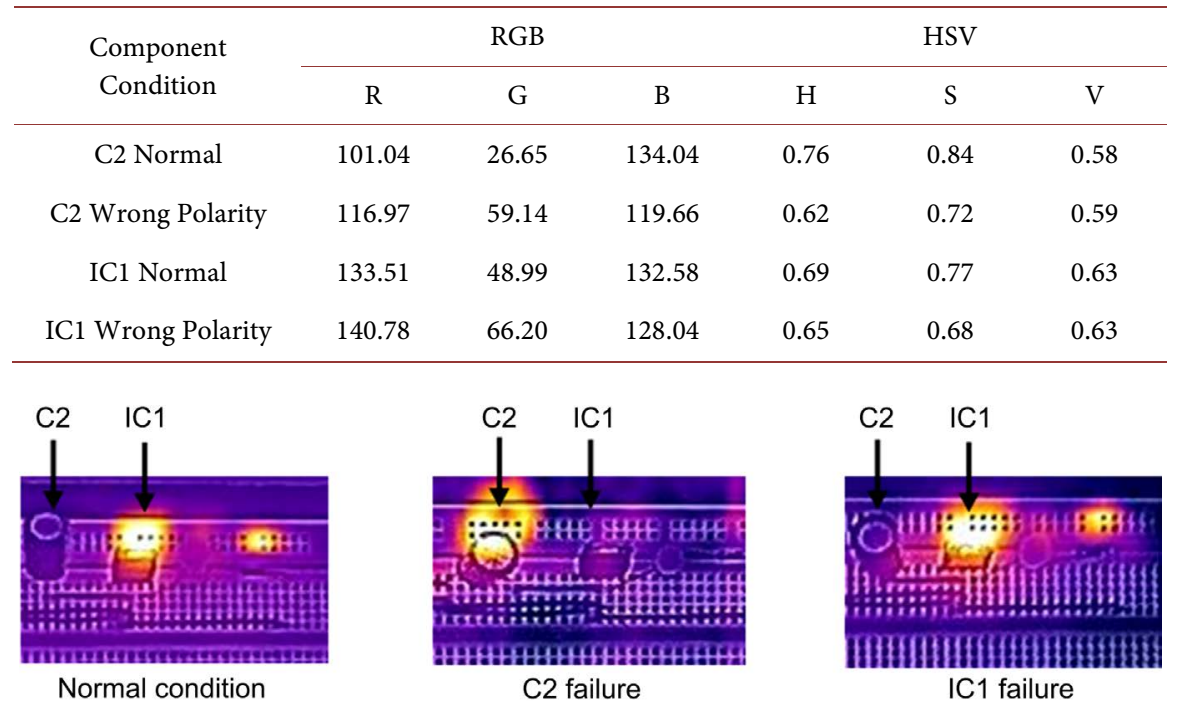

Figure 3. Normal and failure condition image.

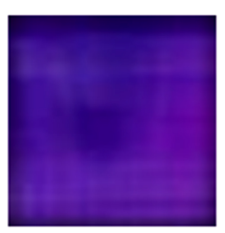

C2 Normal

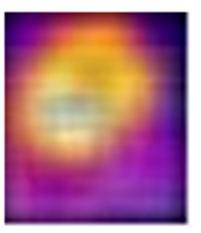

C2 failure

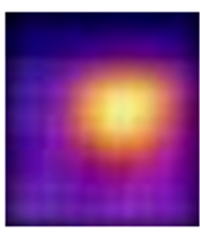

IC1 Normal

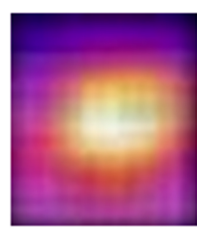

IC1 failure

Figure 4. Normal and failure condition image after cropped and filtered.

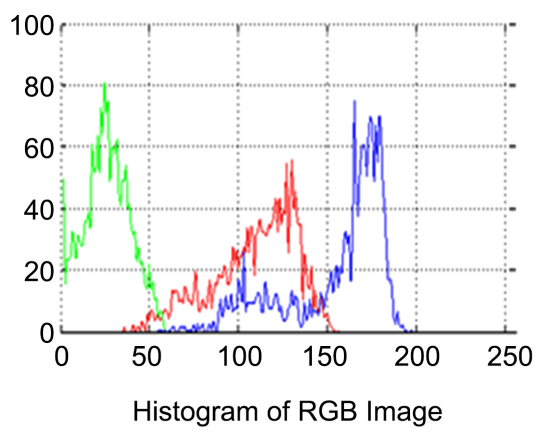

(a)

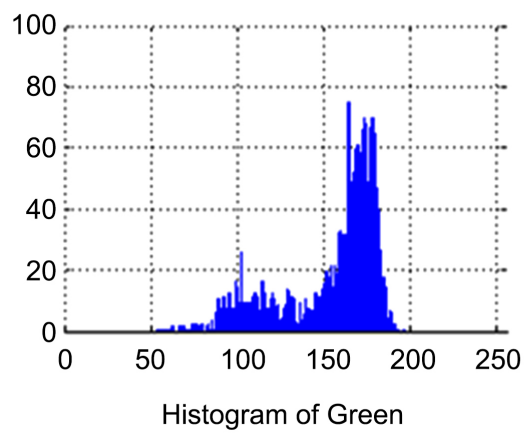

(c)

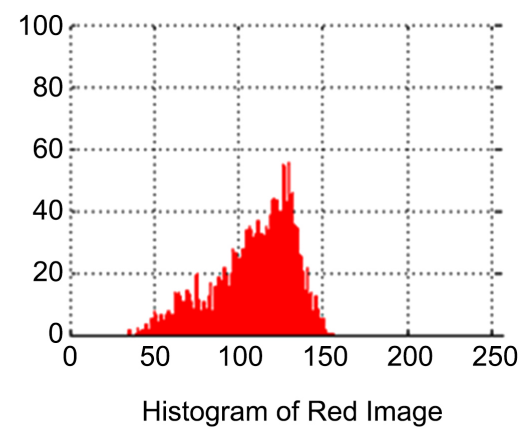

(b)

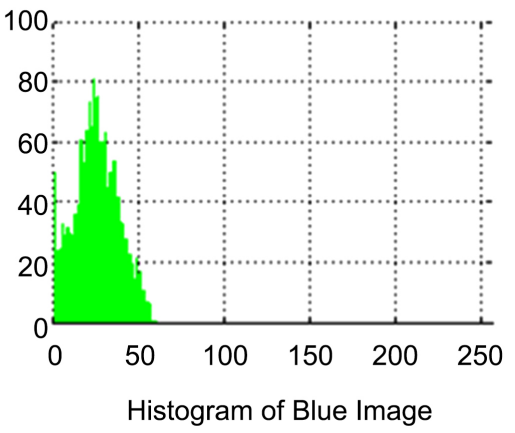

(d)

Figure 5. Normal condition RGB image of Capacitor C2. 


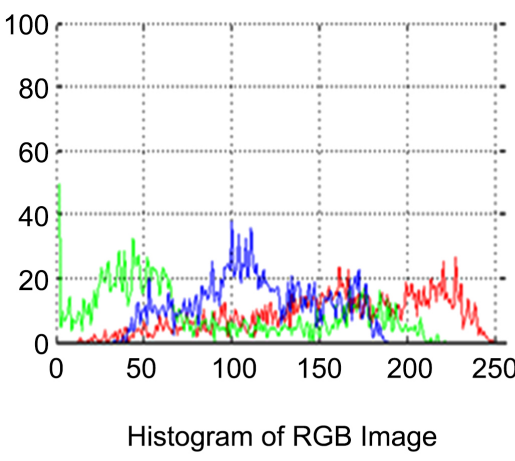

(a)

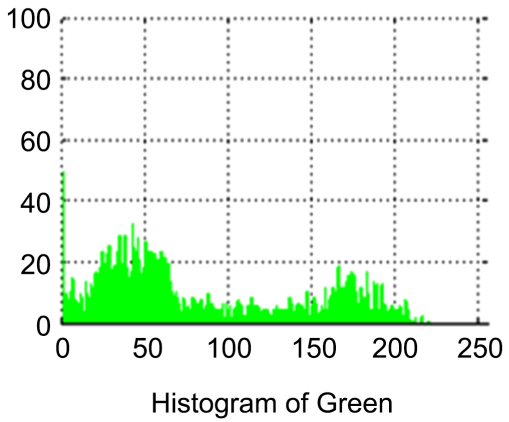

(c)

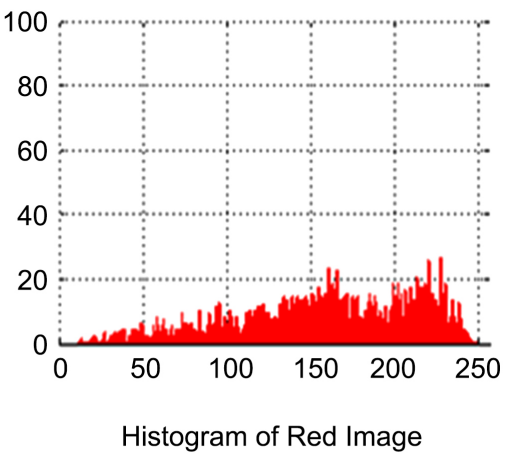

(b)

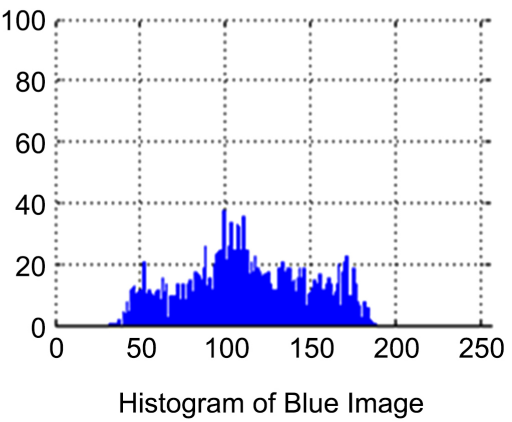

(d)

Figure 6. Wrong polarity condition RGB image of Capacitor C2.

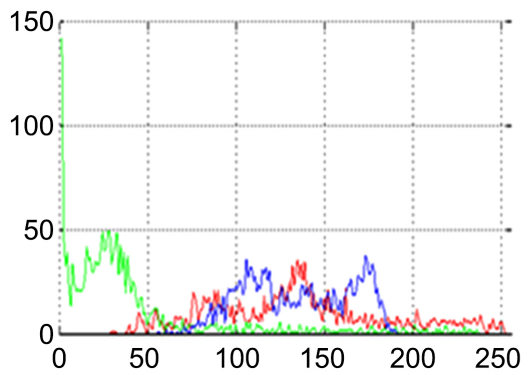

Histogram of RGB Image

(a)

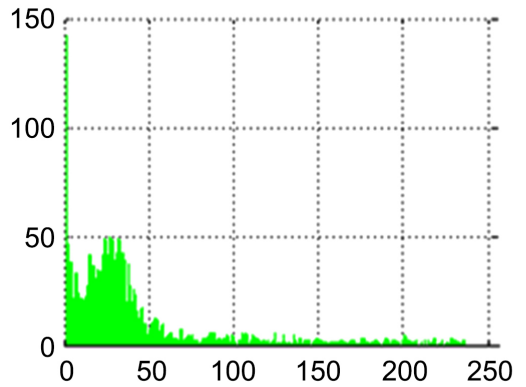

Histogram of Green

(c)

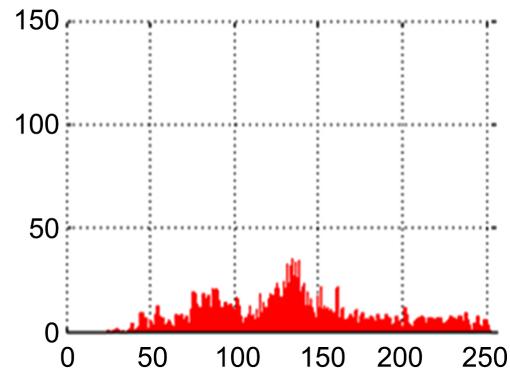

Histogram of Red Image

(b)

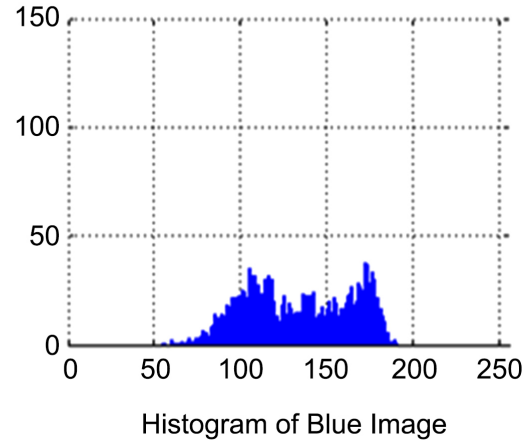

(d)

Figure 7. Normal condition RGB image of IC1. 


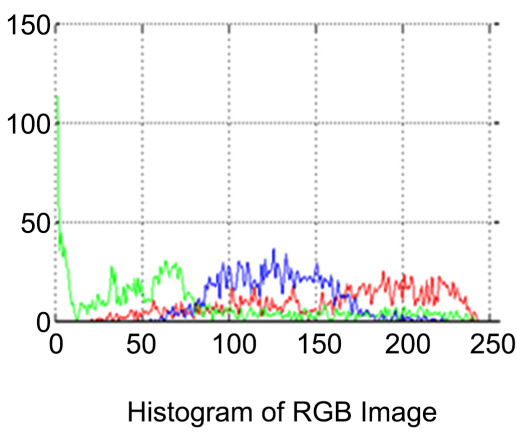

(a)

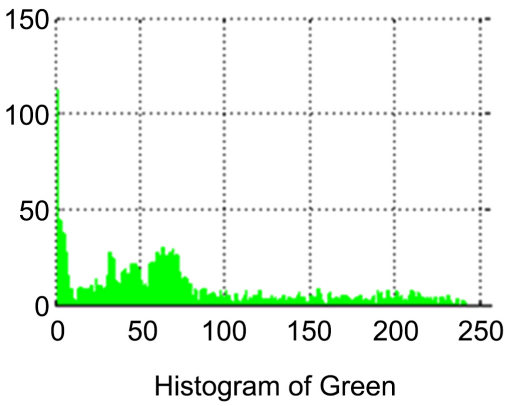

(c)

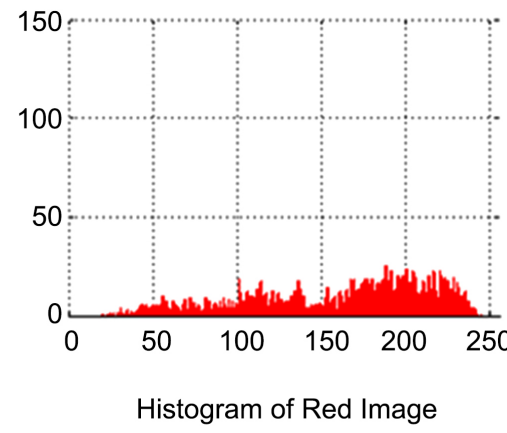

(b)

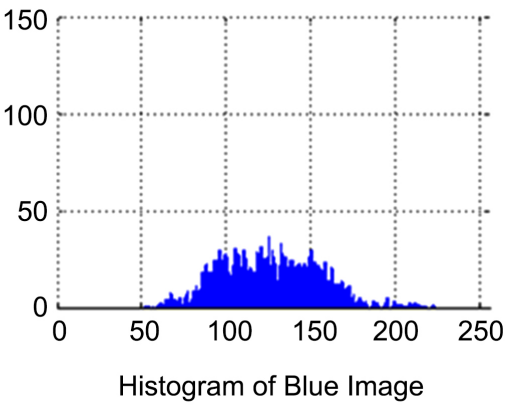

(d)

Figure 8. Wrong polarity condition RGB image of IC1.

\section{Conclusion}

As the conclusion, the study successfully distinguished normal and failure component using image processing. In this study, the influence of environmental temperature has been neglected. The data has been collected in open space within the laboratory. Thus, there is no uniform reference of hot and cold point reference during the experiment. In the future, it is recommended that the experiment be conducted in a closed room and the environmental temperature conditions should be recorded so that the value obtained is more accurate.

\section{Acknowledgements}

Thanks to the Department of Electrical Engineering, Polytechnic Sultan Haji Ahmad Shah for providing facilities and instruments during the experiment. We would also like to thank the laboratory assistant who helped us prepare the material in this study and would not forget all those involved directly and indirectly in completing this study.

\section{Conflicts of Interest}

The authors declare no conflicts of interest regarding the publication of this paper.

\section{References}

[1] Schott, J.R. (1989) Image Processing of Thermal Infrared Images. Photogrammetric 
Engineering and Remote Sensing, 55, 1311-1321.

[2] Jadin, M.S. and Ghazali, K.H. (2014) Gas Leakage Detection Using Thermal Imaging Technique. UKSim-AMSS 16 th International Conference on Computer Modelling and Simulation, Cambridge, 26-28 March 2014, 302-306.

https://doi.org/10.1109/UKSim.2014.95

[3] Shakmak, B. and Al-Habaibeh, A. (2015) Detection of Water Leakage in Buried Pipes Using Infrared Technology, a Comparative Study of Using High and Low Resolution Infrared Cameras for Evaluating Distant Remote Detection. IEEE Jordan Conference on Applied Electrical Engineering and Computing Technologies (AEECT), Amman, 3-5 November 2015, 1-7. https://doi.org/10.1109/AEECT.2015.7360563

[4] Wiecek, B., Danych, R., Zwolenik, Z. and Zuber, J. (2001) Advanced Thermal Image Processing for Medical and Biological Applications. Conference Proceedings of the 23rd Annual International Conference of the IEEE Engineering in Medicine and Biology Society, Istanbul, 25-28 October 2001, 2805-2807.

[5] Hahn, F., Hernández, G., Echeverría, E. andRomanchick, E. (2006) Escherichia coli Detection Using Thermal Images. Canadian Biosystems Engineering, 48, 4.

[6] Zin, A., Hawari, K. and Khamisan, N. (2016) Early Detection of Spots High Water Saturation for Landslide Prediction Using Thermal Imaging Analysis. International Journal of Environmental Science and Development, 7, 41-45. https://doi.org/10.7763/IJESD.2016.V7.738

[7] Kaya, S. (2016) Buried and Surface Mine Detection from Thermal Image Time Series. Master of Science in Geodetic and Geographical Information Technologies, Middle East Technical University, Ankara, Turkey.

[8] Yasaswi, V., et al. (2015) Infrared Thermal Image Segmentation for Fault Detection in Electrical Circuits Using Watershed Algorithm. International Journal of Engineering Trends and Technology (IJETT), 21, No. 9. https://doi.org/10.14445/22315381/IJETT-V21P282

[9] Li, F., Li, J.F., Meng, Y., Tong, R., Liu, R., Zu, B., Liu, W., Liu, L., Wang, Z.X., Cheng, X.J., Chen, G.R. and Liu, M. (2016) An Infrared Detection Method Used in Electrical Equipment Fault Diagnosis. 4th International Conference on Machinery, Materials and Computing Technology (ICMMCT2016). https://doi.org/10.2991/icmmct-16.2016.287

[10] Harishkumar, S., Razick Mohammed, V. and Mohammed Mujtaba, B. (2014) Detection of Hot Spots by Thermal Imaging to Protect Power Equipment. International Journal of Students Research in Technology \& Management, 2, 64-66.

[11] Al-Obaidy, F. (2016) IC Testing Using Thermal Image Based on Intelligent Classification Methods. Master of Applied Science and Computer Engineering, Ryerson University, Toronto.

[12] Glowacz, A., Glowacz, A. and Glowacz, Z. (2017) Detection of Short-Circuits of Dc Motor Using Thermographic Images, Binarization and k-nn Classifier. Technical Gazette, 24, 1013-1018. https://doi.org/10.17559/TV-20150924194102 